\title{
Student Difficulties in Solving Equations from an Operational and a Structural Perspective
}

\author{
Al Jupri ${ }^{1}$, Paul Drijvers ${ }^{2}$ and Marja van den Heuvel-Panhuizen ${ }^{3}$ \\ ${ }^{1}$ Utrecht University, Freudenthal Institute for Science and Mathematics Education, Faculty of \\ Science, Utrecht University, Utrecht, the Netherlands \& Jurusan Pendidikan Matematika, FPMIPA, \\ Universitas Pendidikan Indonesia, Bandung, Indonesia \\ 2 Utrecht University, Freudenthal Institute for Science and Mathematics Education, Faculty of \\ Science, Utrecht University, Utrecht, the Netherlands \\ ${ }^{3}$ Utrecht University, Freudenthal Institute for Science and Mathematics Education, Faculty of \\ Science \& Faculty of Social and Behavioural Sciences, Utrecht University, Utrecht, the Netherlands
}

\begin{abstract}
In Indonesia, as in many other countries, mathematics teachers, educators and researchers are confronted with student difficulties in initial algebra. To investigate and understand these difficulties, we carried out a pilot study involving 51 Indonesian grade seven students who use a digital mathematics environment for algebra. The notions of operational and structural conceptions offer a framework for explaining student difficulties in solving equations. These include difficulties with arithmetical skills, the use of the equal sign, understanding algebraic expressions, and understanding the concept of variable. The operational and structural perspectives provide guidelines for future task design and research.
\end{abstract}

Keywords: Algebra Education, Digital Mathematics Environment, Equations in One Variable, Operational and Structural Views

\section{INTRODUCTION}

Over the last decade Indonesian students had very low performances in mathematics and particularly in algebra, as revealed in the Trends in International Mathematics and Science Study (TIMSS). In TIMSS 2007, on the topic of algebra, Indonesian students were in $36^{\text {th }}$ position out of 48 participating countries (Mullis et al., 2008). In TIMSS 2011, similarly, Indonesian students were in $38^{\text {th }}$ position out of 42 countries (Mullis, Martin, Foy \& Arora, 2012). As an initial step to explain these low performances, an explorative study was carried out to investigate student difficulties in initial algebra learning in Indonesia (Jupri, Drijvers \& Van den Heuvel-Panhuizen, 2014). This study revealed five types of difficulties in initial algebra that relate to a lack of both conceptual understanding and algebraic procedural skills, two competencies that are crucial aspects of the algebraic expertise needed by secondary school students (Bokhove \& Drijvers, 2010; Drijvers, 2010).

In order to acquire a better understanding of these student difficulties, we have conducted a pilot study in which student work on equations in one variable using two applets, one of which invites an operational view on algebraic expressions and the other a more structural view. In this paper we present the findings of this pilot study, whose main results concern the identification of student difficulties and the understanding of these difficulties from both an operational and a structural view on equations and expressions. 
This paper first describes the research aim and theoretical background, including difficulties in initial algebra from the literature; and both operational and structural views on mathematical conceptions. Next, the research question and research method are described. The results section elaborates student difficulties in the light of the operational and structural views. Finally, the conclusion and discussion section reflects on the results which inform future research and task design in particular.

\section{Research Aim and Theoretical Background}

This paper aims to identify student difficulties in initial algebra and in solving equations in one variable in particular which emerge in an Information and Communication Technology (ICT)-rich approach, and to explain the difficulties from operational and structural views on the algebraic activity involved. We argue that this theoretical perspective offers insight into student conceptual difficulties and understanding in the field of initial algebra.

\section{Difficulties in Initial Algebra Learning}

The existing research literature in initial algebra education serves as a frame of reference for this study and has led us to identify five types of difficulties in initial algebra: applying arithmetical operations in numerical and algebraic expressions, understanding the notion of variable, understanding algebraic expressions, understanding the different meanings of the equal sign, and mathematization (Jupri, Drijvers \& Van den Heuvel-Panhuizen, 2014). Let us briefly describe each of these types of difficulties.

First, concerning the category of applying arithmetical operations in numerical and algebraic expressions (abbreviated as the ARITH category), research literature shows that students often fail to add or subtract similar algebraic terms (e.g., Herscovics \& Linchevski, 1994; Linchevski, 1995). Also, students misapply commutative as well as associative properties when carrying out subtractions or divisions (Booth, 1988; Warren, 2003), and fail to use the distributive property of a multiplication over an addition (Booth, 1988). In our view, these difficulties reveal students' limited mastery of addition, subtraction, multiplication and division; of applying the priority rules of arithmetical operations in calculations; and of using properties of numerical operations. These difficulties seem to originate in the way arithmetic is taught at in primary school, focusing on calculation at local level before the problem as a whole is overseen.

Second, concerning the category of understanding the notion of variable (the VAR category), research reveals that students have difficulties to distinguish a literal symbol as a variable that can play several roles, such as the role of a placeholder, a generalized number, an unknown, or a varying quantity (Booth, 1988; Herscovics \& Linchevski, 1994).

Third, the category of understanding algebraic expressions (AE) includes the parsing obstacle (understanding the order in which the algebraic expressions must be processed, which may conflict with the order of natural language), the expected answer obstacle (an incorrect expectation to get a number for an algebraic expression), the lack of closure obstacle (the discomfort in handling algebraic expressions that cannot be simplified any further), and the lack of gestalt view of algebraic expressions (Arcavi, 1994; Tall \& Thomas, 1991).

The fourth category concerns understanding the different meanings of the equal sign (EQS). In arithmetic, the equal sign often invites carrying out a calculation and writing down a numerical answer, whereas in algebra, it usually means is algebraically equivalent to' (Herscovics \& Linchevski, 1994; Kieran, 1981).

The fifth, and final, category of mathematization (MATH) distinguishes horizontal and vertical mathematization. The difficulty in horizontal mathematization concerns going from the world of real phenomena to the world of symbols and vice versa: in other words, to translate back and forth between the world of the problem situation and the world of 
mathematics (Treffers, 1987; Van den Heuvel-Panhuizen, 2003). The difficulty in vertical mathematization concerns dealing with the process of reorganization within the mathematical system itself, that is, the process of moving within the symbolic world (Treffers, 1987; Van den Heuvel-Panhuizen, 2003).

\section{Operational and Structural Views}

The present study addresses the topic of equations in one variable and linear equations in particular, in which the variable appears only on one side of the equation. To understand the difficulties that students encounter while solving these equations, we wonder whether operational and structural views on algebraic activity might offer an insight. These views originate from Sfard's theory of reification-i.e., a transformational process of a process performed on an accepted object to become a new mathematical object. The following two quotations illustrate this duality.

An analysis of different mathematical definitions and representations brings us to the conclusion that abstract notions, such as number or function, can be conceived in two fundamentally different ways: structurally-as objects, and operationally-as processes. These two approaches, although ostensibly incompatible, are in fact complementary. (...) the processes of learning and of problemsolving consist in an intricate interplay between operational and structural conceptions of the same notions. (Sfard, 1991, p.1)

To sum up, the history of numbers has been presented here as a long chain of transitions from operational to structural conceptions: again and again, processes performed on already accepted abstract objects have been converted into compact wholes, or reified (from the Latin word res-a thing), to become a new kind of self-contained static constructs. Our conjecture is that this model can be generalized to fit many other mathematical ideas. (Sfard, 1991, p.14)

In the case of the present study, equations can be conceived from both operational and structural views. For example, in the light of the operational view, the equation $-3(x+1)-22=8$ can be seen as a series of calculational process: Add 1 to a certain given number $(x)$, next multiply by ${ }^{-3}$, and finally subtract by 22 to get 8 ; in the light of the structural view, this equation can be conceived as equivalence between two objects (algebraic expressions), namely the algebraic expressions $-3(x+1)-22$ and 8 . The flexibility in switching this process-object view on algebraic expressions signifies a mature understanding of mathematical thinking (Drijvers, 2003).

According to Sfard, "in the process of concept formation, operational conceptions would precede the structural" (Sfard, 1991, p.10). Furthermore, she distinguishes three hierarchical stages of concept formation: interiorization, condensation, and reification, respectively. In the interiorization stage, a student becomes acquainted with a process, for instance an equation as a calculational process. In the condensation stage, the student is more capable to view a process as a whole. These two stages are gradual processes. The third stage of reification, however, is a sudden process, i.e. "a sudden ability to see something familiar in a totally new light." (Sfard, 1991, p.19). A model of concept formation has a hierarchical character, for instance, a process ${ }^{X}$ becomes an object ${ }^{X}$, next the object $X$ turns into a process $Y$, and the process ${ }^{Y}$ becomes an object $Y$, and so on.

Other theoretical lenses that seem to be more specific within the reification theory and the structural view in particular for algebra are symbol sense and structure sense. The term 'symbol sense', even if it is not precisely defined, refers to an ability to have a feeling for and to give meaning to mathematical symbols such as algebraic expressions, formulas, and equations. Two characteristics of symbol sense which fit with the structural view include an ability to read through and to manipulate algebraic expressions to gain a feel for and an understanding of the problem; and an ability to realize the need to check for the symbols meaning during the implementation of an equation solving procedure or during the inspection of a result (Arcavi, 1994, 2005).

Structure sense, which is a more specific perspective on the structure of algebraic expressions, is a flexible and creative ability to identify all equivalent forms of algebraic 
expressions (Linchevski \& Livneh, 1999). This structure sense idea is elaborated by Hoch and Dreyfus (2009) as well as Novotna and Hoch (2008) for the case of secondary school algebra. Students are said to show structure sense if they can (1) recognize a familiar structure in both its simplest form and in a more complex form, (2) deal with a compound term as a single entity, and (3) choose appropriate manipulations to make best use of a structure. A key feature of structure sense is the substitution principle, i.e., when an algebraic sub-expression is substituted by a dummy variable and vice versa, the structure of the expression as a whole remains the same.

\section{Research Question}

The integration of ICT not only seems to be a promising avenue for improving algebra education (e.g., Bokhove, 2010; Bokhove \& Drijvers, 2010), it may also offer a vehicle to further study student difficulties in initial algebra and in equations in one variable in particular. We argue that identifying student difficulties and understanding these difficulties from operational and structural perspectives can lead to a better insight on student conceptual understanding and skills. Taking the above into account, we formulate the following research question:

What are student difficulties in solving equations in one variable which emerge in an ICTrich approach and how can operational and structural views on equations explain these difficulties?

\section{METHOD}

This section addresses the design of instruments, the participants, the data collection, and the data analysis.

\section{Design of Instruments: Applets and Tasks}

This study is part of a larger project in which a learning arrangement was designed, consisting of student material, including paper-and-pencil tasks, digital tasks, intermediate formative paper-pencil assessment tasks, and a final written test. A teacher guide informs the learning arrangement activities.

The designed learning arrangement includes activities with two applets called Algebra Arrows and Cover-up Strategy, the first one inviting an operational view on algebraic expressions and the second one a more structural view. The first one, Algebra Arrows, is an applet which offers the possibility to construct and use chains of operations on numbers and formulas. Initially, this applet was designed to support the construction of inputoutput chains of operations as a model of a dependency relationship in the function concept (Doorman, Drijvers, Gravemeijer, Boon \& Reed, 2012). In this study, the applet was used to solve equations. Figure 1 shows how the equation $\frac{2 x-7}{3}+11=40$ can be solved using the Algebra Arrows. Solving an equation through this applet is similar to the informal reverse strategy. As an equation can be interpreted as a calculational process, the reverse strategy is essentially a process of undoing this calculational process to find solutions of the equation. Therefore, in our view, this strategy relies on an operational view on equations. Through working with the Algebra Arrows, students are expected to get a better insight into the equation as a calculational process. 


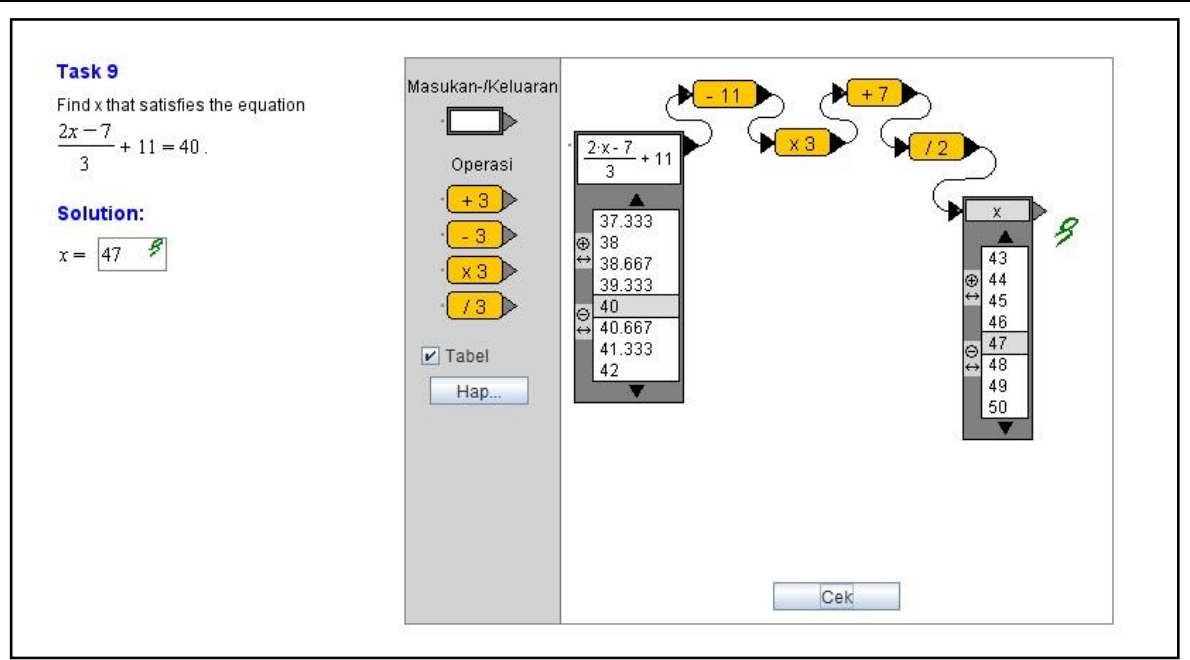

Figure 1. Equation solving with the reverse strategy using the Algebra Arrows applet

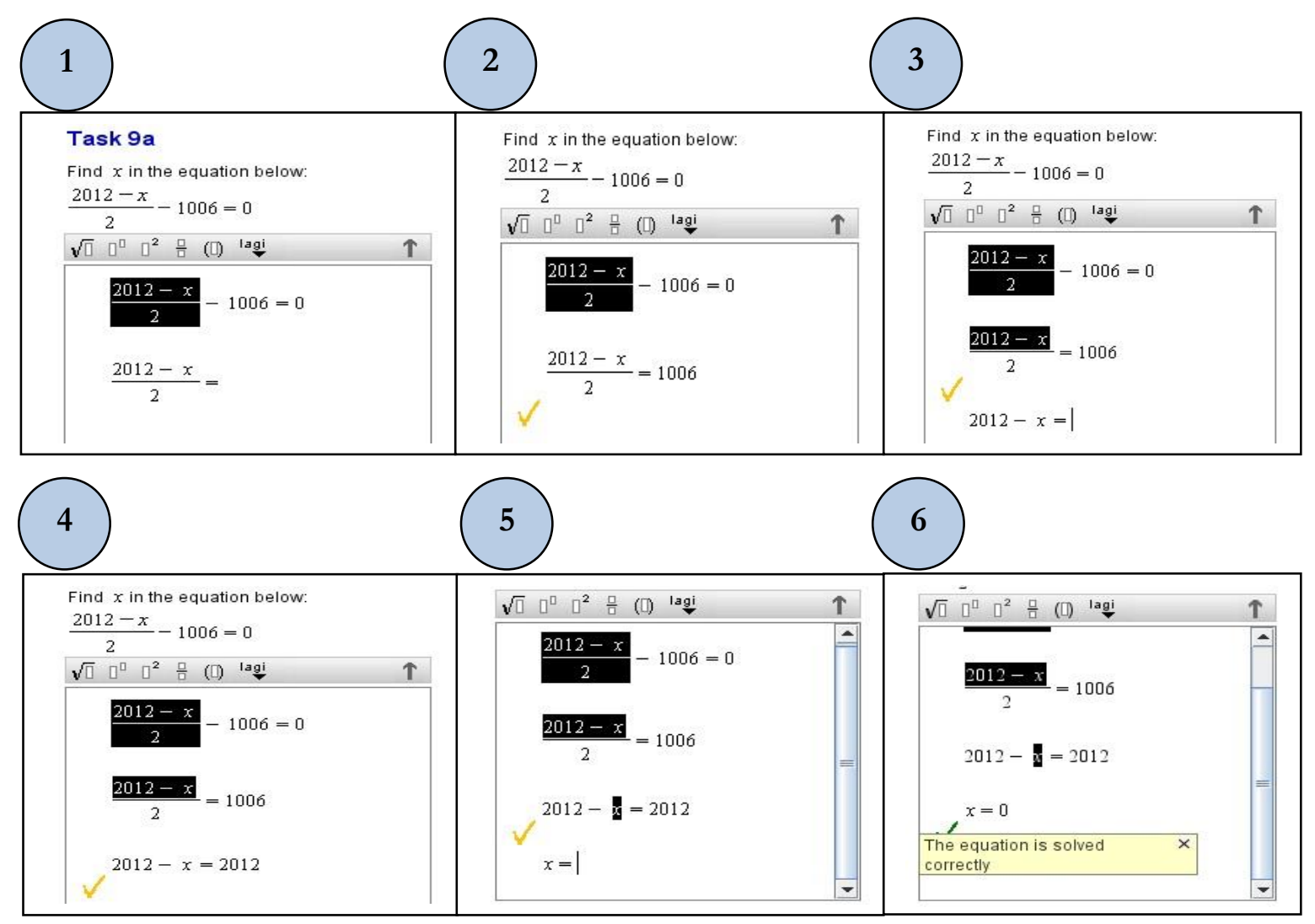

Figure 2. An equation solving scenario using the Cover-up Strategy applet

The second applet, the Cover-up Strategy applet, allows for solving a certain equation type (equations in one variable which appears in one side only) by subsequently selecting a part of the expression in an equation with the mouse and finding its value. For example, Figure 2 shows an equation solving scenario with the cover-up strategy to solve the equation $\frac{2012-x}{2}-1006=0$

expression $\frac{2012-x}{2}$ and the applet provides $\frac{2012-x}{2}=\cdots$ in the next line. In step 2 , the student fills in $\mathbf{1 0 0 6}$, and the applet gives a tick mark which signifies that it is correct (otherwise a cross mark will appear). This scenario proceeds until step 6 and ends up at $x=0$ as the 
solution of the equation (which is signified by the emergence of the final feedback from the applet, namely "The equation is solved correctly!"). To properly apply the cover-up strategy in solving an equation, students should first perceive the equation as an equivalence of two objects (algebraic expressions). Next, in each step they should be able to identify the part (structure) of the equation to be covered. In this way, this strategy relies on a structural view on equations and expressions. Through working with the Cover-up Strategy applet, students are expected to get a better object view on the equation and the algebraic subexpressions that are part of it (Boon, 2006).

For both applets, online student activities were designed focusing on solving linear equations in one variable. Preliminary versions of these activities with the two applets were tested in a group of nine Indonesian master students in mathematics education. Based on this, some improvements were incorporated.

The applets and the online tasks can be accessed through the Digital Mathematics Environment (DME), i.e., a web-based electronic learning environment which offers interactive mathematical tools for algebra, graphing geometry, and other domains. The DME allows for the design of open online tasks and appropriate feedback (Boon, 2006; Drijvers, Boon, Doorman, Bokhove \& Tacoma, 2013). Through the DME students can learn mathematics and in particular algebra with conventional notations and techniques, learn any time and any place (as far as technological conditions are met), and save their work.

The activities with the Algebra Arrows applet took part during the first two lessons of the teaching sequence, whereas lessons 3 and 4 included Cover-up Strategy applet activities. Lesson 5 consisted of a final written test, covering the topics of the four lessons. In the first four lessons the digital activity consisted of a demonstration in which the teacher demonstrated how to work with the applets, group work and discussion. When students worked in groups, the teacher controlled the activity, gave help when necessary and discussed important issues, such as frequent mistakes made while solving the digital tasks.

\section{Participants}

The observations took place in two schools in Indonesia. One class with 41 grade seven students (12-13 year-old) was chosen from the first school, and ten grade seven students (12-13 year-old) participated from the second school. The students from the second school, including high, medium and low achievers, were selected by their mathematics teacher to participate in this study. The experiment as a whole in each school took five 80-minutes lessons.

\section{Data Collection}

Data that were collected from each school consisted of video registrations of four teaching sessions, student written work from each assessment and from the final written test, and field notes.

\section{Analysis of the Data}

The data analysis was carried out in two steps. In the first step, a preliminary analysis on video registration - with software for qualitative analysis (Atlas.ti in this case) - and on student digital group work as well as on individual written work was carried out. With the difficulties in initial algebra as a framework, this preliminary analysis included: marking and transcribing crucial moments in paper-and-pencil activity and in classroom discussions as well as in student digital group work; examining and assigning difficulties on student written work (including the final written test) for each single task (which serves as a unit of analysis). A unit may reveal more than one category of difficulty. This analysis produced results on student difficulties in solving symbolic equation tasks using the two applets. 
The second step of the analysis consisted of an in-depth analysis on student difficulties in solving symbolic equation tasks from the operational and structural perspectives. To confirm the analysis of the written work, transcriptions from observations during the learning activities using the digital technology were used. Thus, the results of the analysis integrate the quantitative data from the intermediate formative assessments and the qualitative analysis of the video data from students' activities in the Digital Mathematics Environment.

\section{FINDINGS}

The results include an analysis of the data of the student work with the two applets as well as the final written test. The main results involve individual written student work after the work with the applets, and are illustrated by student group work in the DME-sessions. The findings from the final written test are used to confirm the results of these analyses.

\section{Student Difficulties While Applying the Reverse Strategy}

The Algebra Arrows activities focused on equation solving with the reverse strategy (RS). A total of fifty students participated in this activity. The results of these students for the four tasks they worked on with paper and pencil at the end of the lesson are summarized in Table 1. Columns 1-5 subsequently present: tasks, number of students who solved the tasks correctly $(\# C)$, type of equation solving strategy used by students, type of student difficulties revealed in each task, and the operational and structural aspects which might explain student difficulties. Corresponding percentages (relative to the total number of participating students) are provided for columns $2-4$.

Table 1. Results from data analysis of the Algebra Arrows lesson $(\mathrm{N}=50)$

\begin{tabular}{|c|c|c|c|c|c|}
\hline \multicolumn{2}{|c|}{ Equations to solve } & $\# \mathrm{C}(\%)$ & Strategy $(\%)$ & Difficulties (\%) & Nature of the difficulties \\
\hline 1. & $2 x-11=29$ & $40(80)$ & RS (100) & $\begin{array}{l}\text { ARITH: inverses }(8) \\
\quad \text { calculational errors }(2) \\
\text { EQS: notational errors }(10)\end{array}$ & $\begin{array}{l}\text { Structural } \\
\text { Operational } \\
\text { Structural }\end{array}$ \\
\hline 2. & $\frac{x}{2 z}-11=10$ & $40(80)$ & RS (100) & $\begin{array}{l}\text { ARITH: calculational errors (2) } \\
\text { EQS: notational errors }(22)\end{array}$ & $\begin{array}{l}\text { Operational } \\
\text { Structural }\end{array}$ \\
\hline 3. & $-3(x+1)-22=8$ & $6(12)$ & RS (100) & $\begin{array}{l}\text { ARITH: priority rules }(32) \\
\text { inverses }(12) \\
\text { calculational errors }(18) \\
\text { EQS: notational errors (16) }\end{array}$ & $\begin{array}{l}\text { Operational \& structural } \\
\text { Structural } \\
\text { Operational } \\
\text { Structural }\end{array}$ \\
\hline 4. & $\frac{x x-7}{x}+3=4$ & $17(34)$ & RS (100) & $\begin{array}{l}\text { ARITH: priority rules }(28) \\
\text { inverses }(8) \\
\text { calculational errors }(22) \\
\text { EQS: notational errors }(44)\end{array}$ & $\begin{array}{l}\text { Operational \& structural } \\
\text { Structural } \\
\text { Operational } \\
\text { Structural }\end{array}$ \\
\hline
\end{tabular}

Tasks 3 and 4 seem to be difficult for most students. Six students (12\%) solved task 3 correctly; and seventeen students (34\%) solved task 4 correctly. Although there were students who solved tasks 1 and 2 incorrectly, the frequencies were not high $(20 \%)$. As this lesson dealt with the reverse strategy, it is no wonder that all students used this strategy to solve the tasks. However, we noted that the strategy used by students had differences in terms of representations, namely the reverse strategy with and without arrow chains. Next, the types of difficulties that emerged in student work included the arithmetical (ARITH) and the equal sign (EQS) category. Mistakes in applying priority rules, in calculations (mainly) dealing with negative numbers and fractions, and in inverses were three sub-categories within the ARITH category, while the notational error of the use of the equal sign was a sub- 
category within the EQS category. Finally, concerning the use of the operational and structural views, the lack of an operational view may explain the occurrences of calculational errors; the lack of a structural view may explain the occurrences of mistakes in additive or multiplicative inverses and notational errors of the use of the equal sign; and the lack of both operational and structural views can explain mistakes in applying priority rules of arithmetical operations. In other words, lack of either the operational or structural view or of both views on equations might cause these types of difficulties. For example, mistakes in priority rules might happen because students lacked the operational and structural views on equations.

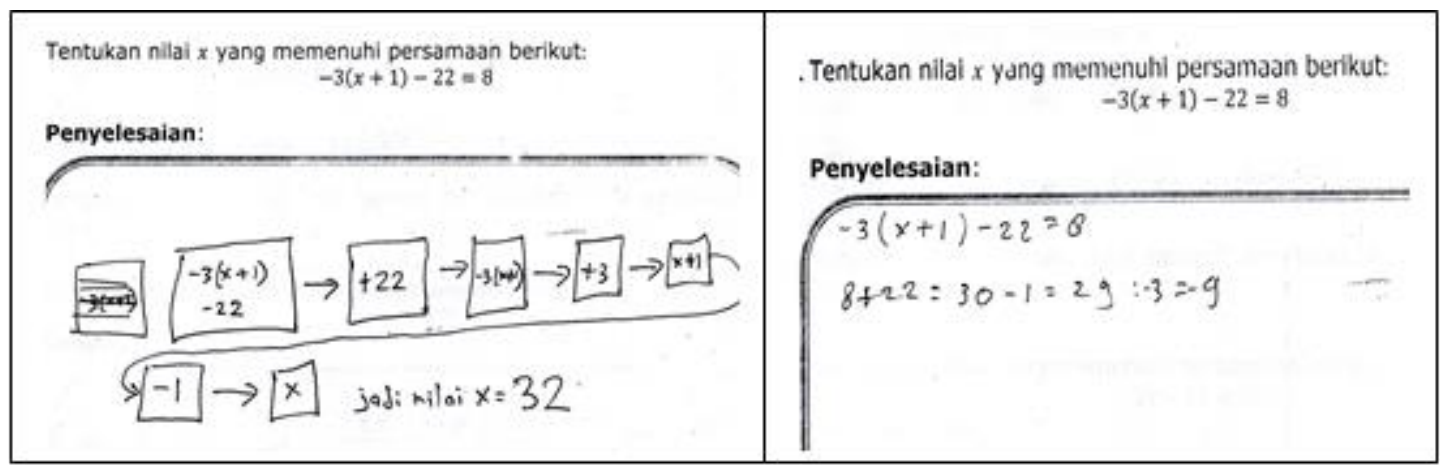

Figure 3. Representative examples of written student work on task 3

To illustrate these findings, we present two representative examples from written student work on task 3. Figure 3 (left screen) shows an example of student work containing an ARITH category of difficulty and the use of the reverse strategy with arrow chains. The difficulty concerns a mistake in using the additive rather than multiplicative inverse: instead of dividing by ${ }^{-3}$ to get $(x+1)$, the student added ${ }^{+3}$. This mistake seems to occur because the student did not understand the meaning of the algebraic expression $-3(x+1)$ as a multiplication of -3 and $(x+1)$. In other words, the student lacked structure sense, which has to do with the structural view on the equation.

Figure 3 (right screen) shows an example of student work containing the ARITH and EQS category of difficulties and the use of the reverse strategy without arrow chains. The ARITH category includes mistakes in applying priority rules of arithmetical operations and in calculation dealing with fractions; and the EQS category includes notational errors in the use of the equal sign. In the light of the operational view, the priority rules mistake seems to occur because the student did not understand the equation as a calculational process, and was not able to undo this process properly: after adding 22 to 8 to get 30, the student did a subtraction of 1 and a division by ${ }^{-3}$ afterwards, rather than to do a division by -3 and a subtraction of 1 respectively to get the solution. In the light of the structural view, this mistake seems to emerge because the student did not understand the expression $-3(x+1)$ as a multiplication of -3 and $(x+1)$, which means that the student lacked structure sense. A similar priority rules mistake working on the equation $3(2 x-1)+7=28$ which has a similar structure to task 3 , taken from observation shown in the following transcript, corroborates this finding.

A pair of students is working on the equation $3(2 x-1)+7=28$ and the researcher is observing.

Student 1: [Using the Algebra Arrows, he will simplify $3(2 x-1)+7$. First, he would like to

subtract 7 from this expression].

Student 2: [It must first be] divided by [3]!

Student 1: No. [It should be subtracted by 7. Student 2 does not complain because the expression

becomes simpler into $3(2 x-1)$. Student 1 will simplify $3(2 x-1)$ by adding +1$]$.

Student 2: It should be subtracted [by 1]. 
Student 1: No. It is minus [within $2 x-1$ ], is not it? So 1 must be added. [He comes up with the Figure 4].

Student $1 \& 2$ : [Laughing]. It is bigger [and more complicated]!

Student 2: So, it is incorrect! [He erases the incorrect part, but seems not to know what to do next.]

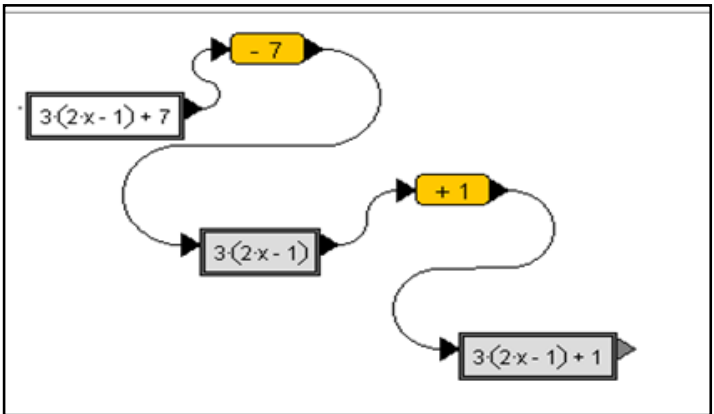

Figure 4. A priority rules mistake in Algebra Arrows applet environment

Even if the calculational error dealing with a division (fractions) has to do with arithmetical skills, we perceive this as the lack of an operational view on the equation, namely the inability to do or to undo a calculational process properly. Finally, we conceive that the notational errors in the use of the equal sign were a consequence of the use of the reverse strategy in the equation solving, which has to do with lacking a structural view of the meaning of the equal sign as an equivalent relation between two (algebraic or numerical) expressions.

\section{Student Difficulties While Applying the Cover-Up Strategy}

The Cover-up activity focused on solving equations with the cover-up strategy (CS). In total, 51 students participated in this lesson. Table 2, which has the same headings as Table 1, summarizes the results of these students on the four tasks they worked on with paper and pencil at the end of the lesson.

First, concerning the number of students who solved the tasks correctly (\#C), tasks 6,7 and 8 seem to be difficult for most of students. Five students $(10 \%)$ solved task 6 correctly; thirteen students $(25 \%)$ solved task 7 correctly; and three students $(6 \%)$ solved task 8 correctly. Although there were students who solved task 5 incorrectly, the frequency was not high (24\%). Second, concerning strategy, even if this lesson focused on the cover-up strategy use, the data showed that not all students used this strategy to solve tasks 5-8: The reverse strategy (RS) was still used. Third, regarding difficulties, the ARITH and the EQS category appeared in student work with the reverse strategy, while the ARITH, EQS, and $\mathrm{AE}$ category emerged in student work with the cover-up strategy. If we zoomed in on student work where the reverse strategy was applied, the mistakes in applying priority rules, calculational errors, and inverses were sub-categories within the ARITH category; and notational errors in the use of the equal sign was a sub-category within the EQS category. These results were in line with the findings in the Algebra Arrows activity. Closely looking at student work with the cover-up strategy, sub-categories of difficulties within the ARITH category included calculational errors dealing with negative numbers and fractions, and inverses. Although the EQS category and in particular notational errors in the use of the equal sign appeared, the number was not as frequent as the number of the same mistakes in student work with the reverse strategy. The AE category (the parsing obstacle and lack of closure obstacle) of difficulty emerged in student work with the cover-up strategy, but not in student work with the reverse strategy. Fourth, and final, concerning operational and structural views, the lack of an operational conception may explain the occurrences of calculational errors; the lack of a structural conception may explain the occurrences of mistakes in additive or multiplicative inverses and notational errors of the use of the equal sign; and the lack of both operational and structural views may explain the occurrences of 
mistakes in applying priority rules of arithmetical operations, parsing obstacle and lack of closure obstacle. In other words, these mistakes occurred because of a lack of either the operational or structural view or of both views on equations. For instance, the inverse mistake occurred because students lacked the structural view on equations.

Table 2.Results from data analysis of the Cover-up lesson ( $\mathrm{N}=51)$

\begin{tabular}{|c|c|c|c|c|c|}
\hline \multicolumn{2}{|c|}{ Equations to solve } & \multirow{2}{*}{$\begin{array}{l}\text { \#C (\%) } \\
39(76)\end{array}$} & \multirow{2}{*}{$\begin{array}{l}\text { Strategy }(\%) \\
\text { CS (65) }\end{array}$} & \multirow{2}{*}{$\begin{array}{l}\text { Difficulties }(\%) \\
\text { ARITH: inverses (6) } \\
\quad \text { calculational errors (4) } \\
\text { EQS: notational errors (2) }\end{array}$} & \multirow{2}{*}{$\begin{array}{l}\text { Nature of the difficulties } \\
\text { Structural } \\
\text { Operational } \\
\text { Structural }\end{array}$} \\
\hline 5. & $7(x+1)=49$ & & & & \\
\hline & & & RS (35) & $\begin{array}{l}\text { ARITH: priority rules }(4) \\
\text { EQS: notational errors (12) }\end{array}$ & $\begin{array}{l}\text { Operational \& structural } \\
\text { Structural }\end{array}$ \\
\hline \multirow[t]{2}{*}{6.} & $\frac{y}{z-x}=1$ & $5(10)$ & CS (68) & $\begin{array}{l}\text { ARITH: calculational errors (26) } \\
\text { EQS: notational errors (8) } \\
\text { AE: lack of closure }(2)\end{array}$ & $\begin{array}{l}\text { Operational } \\
\text { Structural } \\
\text { Operational \& structural }\end{array}$ \\
\hline & & & RS (32) & $\begin{array}{l}\text { ARITH: calculational errors ( } 21) \\
\text { EQS: notational errors (4) }\end{array}$ & $\begin{array}{l}\text { Operational } \\
\text { Structural }\end{array}$ \\
\hline \multirow[t]{2}{*}{7.} & $\frac{\mathrm{x} x-5}{9}+8=11$ & $13(25)$ & CS (61) & $\begin{array}{l}\text { ARITH: inverses (8) } \\
\quad \text { calculational errors ( } 35) \\
\text { EQS: notational errors (4) }\end{array}$ & $\begin{array}{l}\text { Structural } \\
\text { Operational } \\
\text { Structural }\end{array}$ \\
\hline & & & RS (39) & $\begin{array}{l}\text { ARITH: priority rules }(12) \\
\text { inverses }(10) \\
\text { calculational errors }(6) \\
\text { EQS: notational errors }(6)\end{array}$ & $\begin{array}{l}\text { Operational \& structural } \\
\text { Structural } \\
\text { Operational } \\
\text { Structural }\end{array}$ \\
\hline \multirow[t]{2}{*}{8.} & $6+7(4-5 x)=20$ & $3(6)$ & CS (39) & $\begin{array}{l}\text { ARITH: calculational errors (29) } \\
\text { AE: parsing obstacle (4) }\end{array}$ & $\begin{array}{l}\text { Operational } \\
\text { Operational \& structural }\end{array}$ \\
\hline & & & RS (61) & $\begin{array}{l}\text { ARITH: priority rules }(45) \\
\quad \text { calculational errors }(16) \\
\text { EQS: notational errors }(25)\end{array}$ & $\begin{array}{l}\text { Operational \& structural } \\
\text { Operational } \\
\text { Structural }\end{array}$ \\
\hline
\end{tabular}

To illustrate these findings, we elaborate two representative examples from written student work on task 8. Figure 5 (left screen) shows an example of student work with the cover-up strategy containing the $\mathrm{AE}$ category of difficulty and the parsing obstacle in particular, that is, the student did not understand the order in which the algebraic expression $6+7(4-5 x)$ must be processed. In the light of the operational view, it seems that the student did not understand the meaning of the equation as a calculational process properly: multiply a given number $(x)$ by 5 , next this is subtracted from 4 , then multiply by 7 , and finally add 6 to get 20. Rather, the student understood the equation as $6+7=13$, and add $(4-5 x)$ to get 20 . In the light of the structural view, the student seems to fail at choosing the first part (structure) of the equation to be covered to get a next step: the student covered $(4-5 x)$ directly rather than $7(4-5 x)$. This means the student did not understand how to carry out the cover-up strategy. As a consequence, we perceive this as lack of a structural view on the equation and of structure sense in particular. 


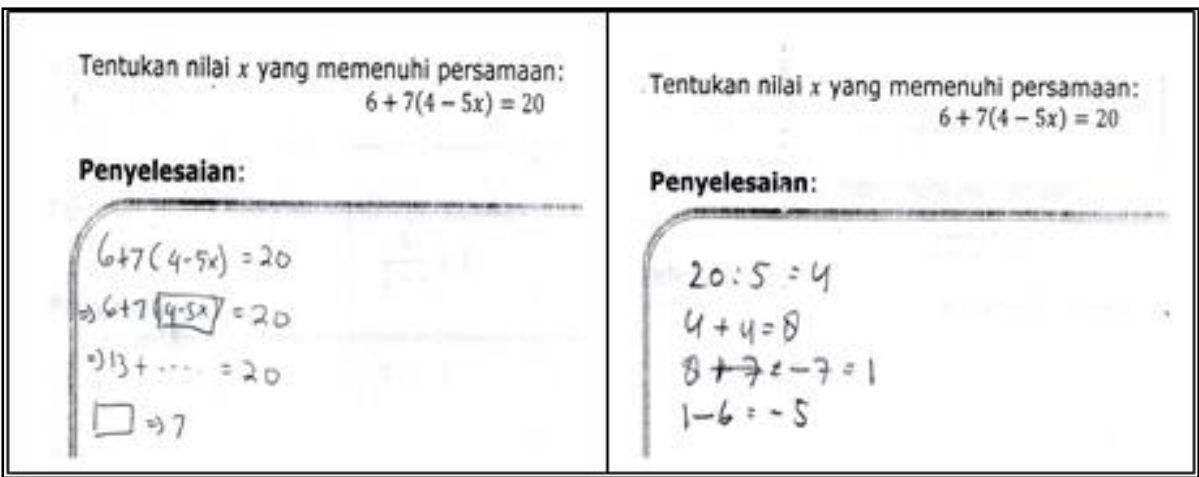

Figure 5. Representative examples of written student work on task 8

Failures to perform the cover-up strategy properly were also observed in the learning processes in both two participating schools, described in the transcript below.

The teacher, in school one, after observing students directly highlight $x$ while doing $5(x+1)=40$, which causes a difficulty in determining the ${ }^{X}$ value, suggests to all students that the expression that must be covered first is $(x+1)$. They seem to follow this suggestion. However, we still observe this same mistake when students work on the equation $7(3 x-2)-2=5$.

A similar difficulty occurs in school two. The teacher observes a pair of students working on $6 x+7=19$. The students seem to not know what to fill in after getting $x=\cdots$ (Figure 6, left screen).

Teacher: If you have this equation $6 x+7=19]$, what should be covered first?

Students $1 \& 2$ : [They keep silent. The teacher reminds them of her example in the demonstration.

Next, Student 1 covers $6 x$, but does not know what to do next.]

Teacher: So, what is the value of $6 x=\cdots$ ? [No reply. The teacher explains that $6 x+7=19$ means "blah-blah-blah added to 7 equals 19".]

Student 2: So, it is 12.

Student 1: [He fills in 12 and gets $6 x=12$ as in Figure 6, right screen]

Teacher: Good! Now you can cover-up ${ }^{x}$. [Student 1 covers-up ${ }^{x}$ and fills in 2 which is the correct solution of the equation, with the applet providing a final feedback].

\begin{tabular}{|c|c|}
\hline $\begin{array}{l}\text { Carilan nilai } x \text { dari persamaan: } \\
6 x+7=19 \\
\sqrt{\sqrt{0} \square^{\square} \square^{2}} \frac{\square}{\square} \text { (品 lagi }\end{array}$ & $\begin{array}{l}\text { Carilan nilai } x \text { dari persamaan: } \\
6 x+7=19 \\
\sqrt{\square} \square^{\square} \square^{2} \text { ㅁㅁㅁ (ㅁ) lagi }\end{array}$ \\
\hline $6 \cdot x+7=19$ & $6 \cdot x+7=19$ \\
\hline$x=$ & $6 \cdot x=12$ \\
\hline
\end{tabular}

Figure 6. Student work in the Cover-up Strategy applet environment

Figure 5 (right screen) contains student work with the reverse strategy showing the ARITH category of difficulty, and priority rules of arithmetical operations mistakes in particular. In the light of the operational view, this type of mistake seems to occur because the student did not understand the equation as a calculational process, and was not able to undo this process properly: rather than subtract 6 , the student divided by 5 first, and so on. In the light of the structural view, this mistake seems to occur because the student did not understand the expression $7(4-5 x)$ as a multiplication of 7 and $(4-5 x)$, which means that the student lacked structure sense. 


\section{Confirmation of Student Difficulties from the Final Written Test}

Were the results of the Algebra Arrows and Cover-up activities confirmed by the final written test data? A total of 47 students from schools one and two participated in the final written test. Table 3, which has the same headings as Table 1, summarizes the results of these students on the two tasks they worked on with paper and pencil in this test. It shows that task 9 seems to be easy (94\% of students solved it correctly), but task 10 seems to be difficult for most of the students (4\% of students solved it correctly). Furthermore, as found in the Cover-up activity data, the type of strategies revealed in student work consisted of the cover-up (CS) and the reverse strategy (RS).

Table 3. Results from data analysis of the final written test $(\mathrm{N}=47)$

\begin{tabular}{|c|c|c|c|c|c|}
\hline \multicolumn{2}{|c|}{ Equations to solve } & $\# C(\%)$ & Strategy $(\%)$ & Difficulties (\%) & Nature of the difficulties \\
\hline \multirow[t]{2}{*}{9.} & $12 x+1=49$ & $44(94)$ & CS (38) & ARITH: inverses (4) & Structural \\
\hline & & & RS (62) & $\begin{array}{l}\text { ARITH: priority rules }(2) \\
\text { EQS: notational errors }(9)\end{array}$ & $\begin{array}{l}\text { Operational \& structural } \\
\text { Structural }\end{array}$ \\
\hline \multirow[t]{2}{*}{10.} & $\frac{4[\sqrt{2}-7 x]}{8}-3=1$ & $2(4)$ & CS (55) & $\begin{array}{l}\text { ARITH: calculational errors (47) } \\
\text { VAR: unknown }(6)\end{array}$ & $\begin{array}{l}\text { Operational } \\
\text { Structural }\end{array}$ \\
\hline & & & RS (45) & $\begin{array}{l}\text { ARITH: priority rules (32) } \\
\text { calculational errors (6) } \\
\text { inverses (4) } \\
\text { EQS: notational errors (13) }\end{array}$ & $\begin{array}{l}\text { Operational \& structural } \\
\text { Operational } \\
\text { Structural } \\
\text { Structural }\end{array}$ \\
\hline
\end{tabular}

In relation to the use of the reverse strategy, types of difficulty emerged in the data included the ARITH category (mistakes in applying priority rules, calculational errors and inverses) and the EQS category (notational errors in the use of the equal sign). These findings confirm the applets activity data. In relation to the cover-up strategy, the types of difficulty consisted of the ARITH (calculational errors, and inverses mistakes) and the VAR category (understanding the variable as an unknown). This means that not all types of difficulties that appeared in the final test also appeared in the Cover-up observational data and vice versa. For example, the VAR category and understanding of the variable as an unknown in particular is a type of difficulty that did not appear in the Cover-up lesson, but did show up in the final test data.

Concerning the role of the operational and structural perspective, similar to the data in Table 2, the lack of the operational view may explain the occurrences of calculational errors; the lack of the structural view can explain the occurrences of mistakes in additive or multiplicative inverses, notational errors of the use of the equal sign, and in understanding the variable as an unknown; and the lack of both operational and structural views may explain the occurrences of mistakes in applying priority rules of arithmetical operations.

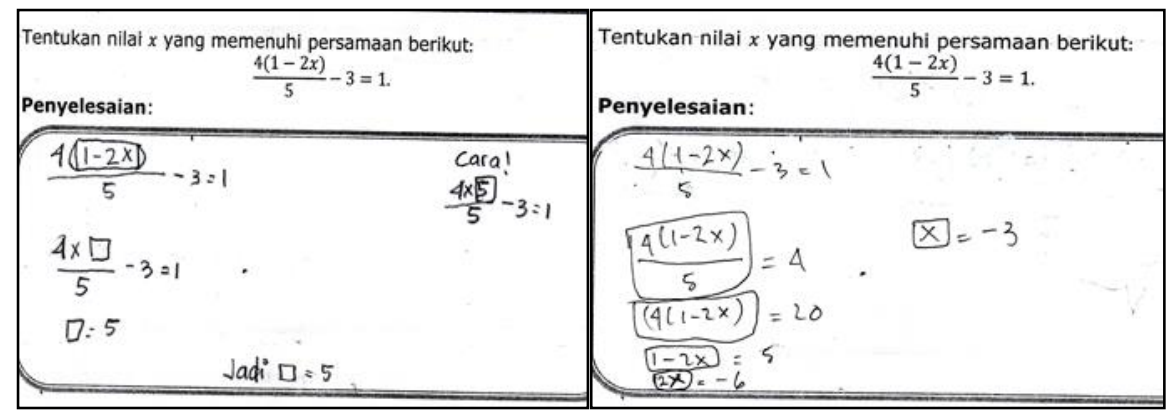

Figure 7. Representative examples of written student work on task 10 
To illustrate these findings, we present representative examples of student work on task 10. Figure 7 (left screen) shows an example of student work with the cover-up strategy containing the VAR category and understanding the variable as an unknown in particular. Although the student seems to be able to identify sub-expressions within the equation that must be covered, she seems to forget that the final goal of equation solving is to find the value of ${ }^{x}$ rather than to end up at a box-which represents $1-2 x$. The decision to end with this box may indicate that she lacked symbol sense (checking the solution in particular), which means lacking a structural view on the equation.

Figure 7 (right screen) illustrates student work with the cover-up strategy containing an ARITH category and a calculational error dealing with negative numbers in particular: rather than to conclude $2 x=-4$ from $1-2 x=5$, the student deduced $2 x=-6$. Our interpretation is that this calculational error signifies a lacking operational view on the equation and on performing arithmetical calculations in particular.

\section{CONCLUSIONS AND DISCUSSION}

The research question addressed in this paper concerns the identification of student difficulties in solving equations which emerge in the ICT-rich approach, and the understanding of these difficulties from operational and structural views. The results lead to the following conclusions. The difficulties that appeared in student work can be classified in two classes related to the equation solving strategies. First, while applying the reverse strategy (frequent in using the Algebra Arrows applet), the main difficulties include arithmetical skills and the equal sign category. The arithmetical skills category concerns mistakes in applying priority rules of arithmetical operations, in determining additive or multiplicative inverses, and calculational errors dealing with negative numbers and fractions. The equal sign category encompasses notational errors in the use of the equal sign only.

Second, while using the cover-up strategy (which relates to the Cover-up Strategy applet), the main difficulties are in the arithmetical skills category, including calculational errors dealing with negative numbers and fractions, and mistakes in determining additive or multiplicative inverses; understanding the concept of variable category and understanding the variable as an unknown in particular; understanding algebraic expressions category, including the parsing obstacle and the lack of closure obstacle; and the equal sign category, and notational errors of the use of the equal sign in particular.

Our analysis of the data suggests that limited operational and structural understanding of equations may explain these difficulties. A limited operational view may account for calculational errors, e.g., dealing with negative numbers and fractions, in the sense that these errors reflect an inability to do or undo a proper calculational process and, as such, limited operational view on equations. A limited structural view on equations may explain mistakes in additive or multiplicative inverses, notational errors of the use of the equal sign, and understanding the variable as an unknown. Mistakes in additive or multiplicative inverses may be caused by a lack of insight in the structure of algebraic expressions involved, and, for instance, mixing up multiplication and addition of sub-expressions. Notational errors concerning the equal sign may result from a lacking insight in the structural meaning of the equal sign as expressing an equivalent relation between two expressions. The mistake on understanding a variable as an unknown reflects a lack of symbol sense. Difficulties that may result from both limited operational and structural views on equations include misapplying priority rules of arithmetical operations, the parsing obstacle and the lack of closure obstacle. The priority rules mistakes may be explained by a lack of understanding of expressions as representing ordered calculational processes-which concerns an operational view; and of a misunderstanding of the structure of an algebraic expression. The parsing obstacle and the lack of closure obstacle occur because of a limited understanding of the operational meaning of algebraic expressions as 
representations of calculational processes. This may be caused by following the order of natural language rather than algebraic rules, and by the inability to identify relevant subexpressions in the equation solving process.

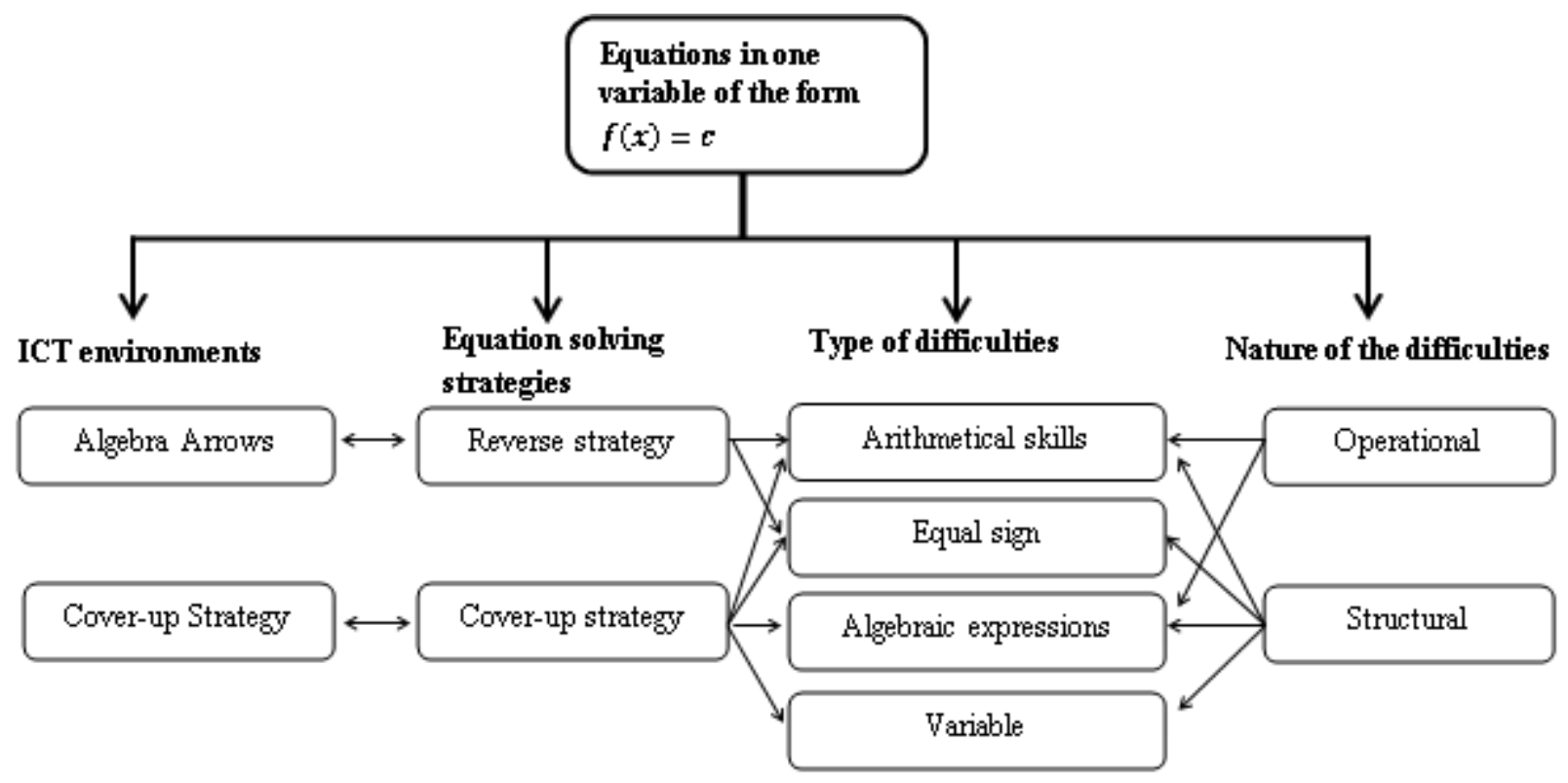

Figure 8. The relations between the study's components

To visualize the study, the diagram in Figure 8 shows the main components and their relationships. It subsequently depicts the ICT environments (applets) involved in this study, the different equation solving strategies included in the teaching sequence, the type of difficulties manifest in student work, and the nature of difficulties from the operational and structural views. The double-sided arrows represent relationships between equation solving strategies and applets; the single-headed arrows connect the strategies to the observed difficulties, and type of difficulties to their operational and structural nature.

Let us briefly reflect on these relationships. Even if we expected students to develop an operational view through the Algebra Arrows activity and a structural view through the Cover-up activity, students' written work revealed considerable difficulties that may be caused by several factors. The first factor concerns student readiness for integrated operational and structural thinking on mathematical conceptions. The process-object views signify a mature understanding of mathematical thinking which may only be reached in higher grades of secondary school (Drijvers, 2003), which participants in this study, who are in the transition phase from primary to secondary level, do not yet have. These students are not ready to develop integrated and flexible operational and structural views on equations and algebraic expressions. In terms of Skemp's (1976) vocabulary, students are not yet prepared to reach relational understanding-that is knowing what to do and why and-even if Skemp did not mention this explicitly-includes relating operational and structural conceptions-of equations and algebraic expressions. As a consequence, students understand equations and algebraic expressions instrumentally and primarily have a limited operational view on these concepts. The second factor concerns the limited amount of time spent on the intervention. According to Sfard (1991), the reification of a mathematical notion is a long and time consuming process, whereas the ICT intervention in this study took a relatively short period. The third factor concerns the role of ICT in the learning processes. Although the use of ICT may motivate students to engage in the learning of mathematics (e.g., Barkatsas, Kasimatis \& Gialamas, 2009), we consider that the ICT intervention in this study is not yet as effective as intended for integrating the flexible operational and structural conceptions. Whereas Algebra Arrows applet fits to develop an operational conception and the Cover-up Strategy applet is more appropriate to 
promote a structural conception, neither of these is proper for developing both conceptions in a flexible, integrated manner. The fourth factor, related to the third, concerns the teacher's ability to use ICT for promoting operational and structural views. Although this is not the focus of this study, we might pay attention to it in future research by better preparing and training teachers. The fifth and final factor concerns the appropriateness of the designed tasks and their presentation for promoting operational and structural conceptions. The following points may inform task design and presentation for future research:

- To reduce student difficulties in calculational errors dealing with negative numbers and fractions-which is one of the most frequent difficulties revealed in student work-we suggest to designing tasks that consist of equations that avoid these issues. In this way, algebraic difficulties will be isolated and can be addressed in a separate way before returning to arithmetically more complex tasks.

- As a means to foster the development of integrated and flexible operational and structural views on equations and algebraic expressions, an important didactical approach to the reverse and cover-up strategies presented here might provide students with the opportunity to use both strategies for the same equation and to compare the two strategies. Also, the reasons for students to prefer one of the two might be investigated.

- As a didactical idea to promote student development of a structural view, structure sense, and symbol sense, we suggest to confront students at an earlier stage with nonlinear equations that can be solved using the cover-up strategy, such as $\frac{32}{3 x-4}+3=19, \frac{64}{7(x+1)+1}=8$, and $(x+2)^{2}=36$ rather than allowing for this at a later stage. We conjecture that students who are able to solve this type of equations correctly improve on these three notions. This approach also promotes the cover-up rather than the reverse strategy in the equation solving.

- To develop a more general equation solving strategy, and as an addition to the two equation solving strategies which only work for equations of the form $f(x)=c$, we suggest to add the balance strategy. This strategy can be applied to solve equations of the more general form $f(x)=g(x)$, and highlights the notion of algebraic equivalence. Doing so will also provide a more comprehensive insight into student conceptual understanding of and difficulties with the concept of equations in one variable.

\section{Acknowledgments}

This study was funded by the Indonesia Ministry of Education project BERMUTU IDA CREDIT NO.4349-IND, LOAN NO.7476-IND DAN HIBAH TF090794. We would like to thank Jan van Maanen for his valuable and constructive comments and suggestions, and Peter Boon for designing the applets. We also thank the teachers and students for their participation as well as an external assistant for her contributions.

\section{REFERENCES}

Arcavi, A. (1994). Symbol sense: Informal sensemaking in formal mathematics. For the Learning of Mathematics, 14(3), 24-35.

Arcavi, A. (2005). Developing and using symbol sense in mathematics. For the Learning of Mathematics, 14(3), 42-47.

Jupri, A., Drijvers, P., \& Van den HeuvelPanhuizen, M. (2014). Difficulties in initial algebra learning in Indonesia. Mathematics
Education Research Journal. DOI: 10.1007/s 13394-013-0097-0.

Barkatsas, A., Kasimatis, K., \& Gialamas, V. (2009). Learning secondary mathematics with technology: Exploring the complex interrelationship between students' attitudes, engagement, gender and achievement. Computers \& Education, 52(3), 562-570. 
Bokhove, C. (2010). Implementing feedback in a digital tool for symbol sense. International Journal for Technology in Mathematics Education, 17(3), 121-126.

Bokhove, C., \& Drijvers, P. (2010). Symbol sense behavior in digital activities. For the Learning of Mathematics, 30(3), 43-49.

Boon, P. (2006). Designing didactical tools and micro-worlds for mathematics education. In C. Hoyles, J. B. Lagrange, L. H. Son, \& N. Sinclair, Proceedings of the 17th ICMI Study Conference;

http://www.fi.uu.nl/isdde/documents/soft ware_boon.pdf

Booth, L. R. (1988). Children's difficulties in beginning algebra. In A.F. Coxford (Ed.), The ideas of algebra, K-12(1988 Yearbook) (pp. 20-32). Reston, VA: National Council of Teachers of Mathematics.

Doorman, M., Drijvers, P., Gravemeijer, K., Boon, P., \& Reed, H. (2012). Tool use and the development of the function concept: from repeated calculations to functional thinking. International Journal of Science and Mathematics Education, 10(6), 12431267.

Drijvers, P.H.M. (2003). Learning algebra in a computer algebra environment: Design research on the understanding of the concept of parameter. Dissertation. Utrecht, the Netherlands: CD-B Press.

Drijvers, P. (Ed.) (2010). Secondary algebra education. Revisiting topics and themes and exploring the unknown. Rotterdam, the Netherlands: Sense.

Drijvers, P., Boon, P., Doorman, M., Bokhove, C., \& Tacoma, S. (2013). Digital design: RME principles for designing online tasks. ICMI Study 22.

Herscovics, N., \& Linchevski, L. (1994). A cognitive gap between arithmetic and algebra. Educational Studies in Mathematics, 27(1), 59-78.

Hoch, M., \& Dreyfus, T. (2009). Developing Katy's algebraic structure sense. Proceedings of CERME 6; www.inrp.fr/editions/cerme6

Kieran, C. (1981). Concepts associated with the equality symbol. Educational Studies in Mathematics, 12(3), 317-326.

Linchevski, L. (1995). Algebra with numbers and arithmetic with letters: A definition of prealgebra. Journal of Mathematical Behavior, 14(1), 113-120.

Linchevski, L., \& Livneh, D. (1999). Structure sense: The relationship between algebraic and numerical contexts. Educational Studies in Mathematics, 4O(2), 173-196.
Mullis, I.V.S., Martin, M.O., Foy, P., in collaboration with Olson, J.F., Preuschoff, C., Erberber, E., Arora, A., \& Galia, J. (2008). TIMSS 2007 international mathematics report: Findings from IEA's trends in international mathematics and science study at the fourth and eighth grades. Boston: TIMSS \& PIRLS International Study Center.

Mullis, I.V.S., Martin, M.O., Foy, P., \& Arora, A. (2012). TIMSS 2011 international results in mathematics. Boston: TIMSS \& PIRLS International Study Center.

Novotna, J., \& Hoch, M. (2008). How structure sense for algebraic expressions of equations is related to structure sense for abstract algebra. Mathematics Education Research Journal, 20(2), 93-104.

Sfard, A. (1991). On the dual nature of mathematical conceptions: Reflections on processes and objects as different sides of the same coin. Educational Studies in Mathematics, 22(1), 1-36.

Skemp, R. R. (1976). Relational understanding and instrumental understanding. Mathematics Teaching, 77, 20-26.

Tall, D., Thomas, M. (1991). Encouraging versatile thinking in algebra using the computer. Educational Studies in Mathematics, 22(2), 125-147.

Treffers, A. (1987). Three dimensions. A model of goal and theory description in mathematics instruction-The Wiskobas project. Dordrecht, the Netherlands: Kluwer Academic Publishers.

Van den Heuvel-Panhuizen, M. (2003). The didactical use of models in realistic mathematics education: An example from a longitudinal trajectory on percentage. Educational Studies in Mathematics, 54(1) 935.

Warren, E. (2003). The role of arithmetic structure in the transition from arithmetic to algebra. Mathematics Education Research Journal, 15(2), 122-137.

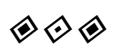




\section{Citation Suggestions :}

APA : Jupri, A., Drijvers, P. \& Van den Heuvel-Panhuizen, M. (2014). Student difficulties in solving equations from an operational and a structural perspective. Mathematics Education, 9(1), 39-55. 